REVISTA DE ESTUDIOS BRASILEÑOS

e-ISSN: 2386-4540

DOI: https://doi.org/10.14201/reb2020714127137

\title{
Gilberto Freyre y Roger Bastide sobre el Oriente íntimo en Brasil: ¿aculturación o transculturación?
}

\author{
Gilberto Freyre e Roger Bastide sobre o Oriente íntimo no Brasil: aculturação ou \\ transculturação? \\ Gilberto Freyre and Roger Bastide on the intimate East in Brazil: acculturation or \\ transculturation?
}

\begin{tabular}{l} 
AUTOR \\
José Antonio \\
González \\
Alcantud* \\
jgonzal@ugr.es \\
\hline \\
*Catedrático de \\
Antropología Social \\
de la Universidad de \\
Granada (UGR, España).
\end{tabular}

RESUMEN:

La comparación de las obras sobre el Oriente y el Islam brasileños de Gilberto Freyre y Roger Bastide, amigos y colaboradores, nos permite plantearnos problemas tales como el de la aculturación y transculturación entre África y América. En este texto, emergen otras figuras de su tiempo como Mariátegui, Arguedas, Fernando Ortiz, Malinowski. En todos ellos late el antirracismo, la vindicación del mestizaje, y la simpatía, vía la Península Ibérica, por los "orientes".

\section{RESUMO:}

A comparação das obras sobre o Oriente e o Islão brasileiros de Gilberto Freyre e Roger Bastide, amigos e colaboradores, permite-nos estabelecer problemas tais como o da aculturação e transculturação entre a África e a América. Neste texto, emergem outras figuras do seu tempo como Mariátegui, Arguedas, Fernando Ortiz, Malinowski. Em todos eles estão presentes o antirracismo, a vindicação da mestiçagem e a simpatia, através da Península Ibérica, pelos "orientes".

\section{ABSTRACT:}

The comparison of the works on the Brazilian East and Islam by Gilberto Freyre and Roger Bastide, friends and collaborators, allows us to consider problems such as acculturation and transculturation between Africa and America. In this text, other figures of his time emerge such as Mariátegui, Arguedas, Fernando Ortiz, Malinowski. In all of them there is anti-racism, vindication of miscegenation, and sympathy, via the Iberian Peninsula, of the "Orient". 
Gilberto Freyre (1900-1987) y Roger Bastide (1898-1974) fueron estrictamente contemporáneos. Sin necesidad de recorrer sus biografías, podemos sintetizar sus recorridos vitales señalando que el primero fue un brasileño cosmopolita que ejerció de profesor en Estados Unidos y Francia, principalmente. Y que el segundo fue un francés de origen "abrasileñado", según cariñosa apreciación de su amigo Freyre. La autoridad de uno y otro se afirmaba en la querencia en el carácter híbrido de la cultura brasileña. Participaban ambos, por lo demás, del espíritu general de la época que consideraba a Brasil "país do futuro", en acertada expresión de Stefan Zweig, el ilustre exiliado europeo en Brasil durante la Segunda Guerra Mundial. Éste había escrito precisamente en su libro sobre Brasil, publicado en 1941, poco antes de suicidarse un año después:

La mezcla, supuestamente destructiva, ese 'pecado contra la sangre' de nuestros teóricos maniáticos de la raza, constituye aquí un medio aglutinante de una cultura nacional, conscientemente utilizado. Sobre este fundamento se viene levantando desde hace cuatro siglos una nación, y - ¡milagro! - la permanente penetración y la adaptación recíproca bajo un mismo clima e idénticas condiciones de vida produjo un tipo absolutamente propio, que no tiene ninguna de las condiciones 'disolventes' proclamadas por los fanáticos de la raza (Zweig, 1941).

Estas posiciones de Zweig fueron consideradas exageradamente laudatorias para un país afectado por diferentes lacras sociales y políticas, y sobre todo por la dictadura del Estado Novo de Getúlio Vargas (1937-1945), con la que se mostró acrítico, quizás por su condición de exiliado. La crítica le vino a Zweig de un sector de los intelectuales brasileños. Sin embargo, como veremos, en realidad tanto Freyre como Bastide siguen en años inmediatamente posteriores en una senda interpretativa muy similar a Stefan Zweig. Parece ser que Zweig además no había leído Casa-grande \& Senzala de Freyre, publicado en 1933, cuando escribió Brasil, país do futuro.

El primer problema es el de la mezcla como principio fundante de Brasil. La concepción sobre el mestizaje o "mezcolanza" siempre estuvo presente en la obra de Gilberto Freyre. Y esta la hace proceder del proceso de conquista y colonización portuguesa. En esta lógica se interroga sobre quiénes son los portugueses desde el punto de vista cultural y "étnico". Sus respuestas en Casa-grande \& Senzala merecen ser expuestas detenidamente:

El portugués es más cosmopolita que el español, es sin embargo el menos gótico de los dos, el más semita, el menos europeo y el más africano; en todo caso el menos definido. El más vago e impreciso como expresión del carácter europeo continental. El más extraeuropeo. El más atlántico (Freyre, 2009, p. 32).

Ahí se configura su particular "oriente", que considera fundamental para explicar el mestizaje brasileño. Emplea mucho en apoyo de sus tesis oriental-iberistas en este dominio al historiador lisboeta Alexandre Herculano (1810-1877) quien sostenía por ejemplo que la vida comunitaria, en los concejos municipales, se había visto incrementada por la presencia moçarabe, y lo justificaba señalando que la mayor parte de los términos para designar lo municipal en Portugal provendría del árabe (Herculano, 1987, p. 31). Herculano habría sido el primero o más importante historiador portugués en el siglo XIX en valorar, tras siglos de ocultación, la aportación islámica a la cultura portuguesa (Hertel, 2015). Esta aportación orientalista no sería sólo una cuestión semántica, sino que indicaría un apego a la vida "patriarcal" de base municipalista, según Freyre. Nuestro autor habría reforzado su manera de ver las cosas tras un viaje a Portugal en 1951-1952, en plena dictadura salazarista.

\section{PALABRAS CLAVE Gilberto Freyre; Roger Bastide; Islam negro; aculturación; transculturación.}

PALAVRAS-CHAVE Gilberto Freyre;

Roger Bastide; Islão negro; aculturação; transculturação.

KEYWORDS

Gilberto Freyre;

Roger Bastide;

Black Islam;

acculturation; transculturation.

Recibido:

12/11/2019

Aceptado:

09/04/2020 
En torno al carácter africano y oriental de los portugueses sugiere Freyre la idea de que el "mozarabismo" y el "semitismo" de estos los abocaría, incluso mucho más que los españoles, a la cosmopolitización y a la adaptación climatológica y social frente a los problemas suscitados por la difícil colonización tropical, nada fácil en comparación con otras como la española, la francesa, la holandesa o la inglesa, con climas y condiciones, según Freyre, mucho más favorables:

Con las ventajas ya indicadas, del portugués del siglo XV sobre otros pueblos colonizadores de la misma época, hace falta añadir su moral sexual, la mozárabe, la católica adaptada en contacto con la mahometana, más laxa, menos sometida a los hombres del Norte. La religión portuguesa no formaba el mismo sistema duro y rígido que aquella de los reformados o la de la Castilla, dramáticamente católica: era una liturgia social más que mística, un dulce cristianismo lírico, con muchas supervivencias fálicas y animistas del antiguo cristianismo (Freyre, 2009, p. 52).

Algunos de estos aspectos dejaron, al decir de Freyre, incluso, en el imaginario colectivo su impronta. Es el caso de la "mora encantada", mujer sensual identificada con el color rojo, que nos dice luego identificaran los colonizadores portugueses en sus deseos tropicales sexuales con las indias (Freyre, 2009, p. 35).

Freyre vuelve sobre el tema de los orientalismos brasileños, oponiéndolos a los occidentalismos en una tenaz lucha. Lo hace en Sobrados e mucambos, publicada en 1939, tres años después de Casa-grande \& Senzala. Allí ejemplifica en el capítulo IX, titulado justamente "O Oriente, e o Ocidente", ese combate con la oposición a la "gelosia de madeira" (celosía de madera), considerada un producto justamente oriental presente en la arquitectura brasileña, símbolo de la resistencia a arquitecturas extrañas (Freyre, 2013).

Recordemos que Casa-grande \& Senzala fue traducida al francés por Roger Bastide en 1952, y publicada con un prólogo del cabeza de lista de la revista-movimiento de renovación historiográfica Annales, Lucien Febvre. Este último, en este prólogo nada circunstancial, se preguntaba cuál era la naturaleza de esta singular obra, si historia o sociología, y se contestaba:

Los hombres de allá, los investigadores libres de la América meridional que se esfuerzan en revivir la que puede ser la más rica de las historias culturales- tiene una suerte de la cual no dudan. Para ir derechos a las realidades, ellos no tienen que atravesar, penosamente, la broza espantosa de estas instituciones, el maquis espinoso de los papeleos administrativos y políticos que, para el menor trabajo, debemos atravesar, calzados con las más altas botas, antes de encontrar al fin, más allá de todos los obstáculos, el hombre vivo, el hombre sensible, el hombre pensante, agitado, creador (Freyre, 2009, p. 21).

Hasta tal punto consideraba Freyre la importancia "moura" en Brasil, siempre a través de la aportación portuguesa, que veía en la arquitectura el ejemplo vivo de su presencia continuada: "A maioria das janelas das casas de residência no Brasil colonial eram de madeira, em estilo mouro" (Freyre, 1971, p. 212). Tendencia que no deja sólo en el pasado, sino que transmite al presente, a la moderna arquitectura, al sostener que esta tendencia "moura" en lo moderno sería una inclinación "doméstica" para compensar la vida pública (Freyre, 1971, p. 225). Así ve, por ejemplo, la impronta "moura" en la moderna arquitectura:

É preciso não esquecer que o caráter doméstico mouro, de alguns dos mais modernos edifícios de apartamentos no Brasil parece ser nova expressão da vitalidade de uma tradição arquitetônica herdada, pelos brasileiros, dos mouros - assim como a romana - através do português. Como resultado dessa herança, transmitida a espaço tropical tão grande como é o Brasil, tal tradição encontrou nesse espaço campo ideal para sua modernização (Freyre, 1971, p. 213).

Por su parte, Roger Bastide fue de los primeros, si no el primero, en prestar atención en el marco de las "religiones africanas en Brasil" al fenómeno del "islã negro" (Bastide, 1971, pp. 203-218). Según Bastide, los esclavos negros que practicaban el islam eran denominados "musulmis" o "malês". Si el primero es claro en su adscripción, el segundo, "malês", haría alusión a su procedencia geográfica, de Mali, región en la 
curva del río Níger caracterizada por ser la frontera, según la describe el explorador Mungo Park en el siglo XVIII, entre el fetichismo y la religión islámica en expansión. Es una región donde hoy día mismo se produce una suerte de fusión muy particular entre islam y creencias fetichistas, a través sobre todo de los cheik o santones, y de la creencia en los djinns, o espíritus demoniacos, aceptados en la ortodoxia islámica, como una fuente esencial de su reflexión y prácticas, imbricados con el fetichismo procedente de las religiones naturalistas o llamadas tradicionalmente "fetichistas" (De Diego, 2019).

Vicent Monteil, cuando abordó el islam negro, término que considera que no es del gusto de los musulmanes, se hace eco de la relación histórica con Brasil. Después de dar cuenta, a través de la información de Roquete Pinto, que en 1922 se consideraba que el $47 \%$ de la población de Brasil era de origen africano, y mayoritariamente de esclavos negros, llegados entre los siglos XVI y XIX, destaca que "entre ellos, llamados generalmente Malês (es decir, venidos de Mali), que tenían en el siglo XIX, y notablemente en Bahía, una religión sincrética, por la contaminación del islam con el animismo dahomeyano". Destaca que, en todo caso, que se observan en los cultos "las deformaciones negro-africanas más extravagantes" (Monteil, 1964, p. 47).

Roger Bastide trae a colación, además, una opinión del conde de Gobineau, quien, siendo embajador galo en Río de Janeiro, informaba que se vendían en esta ciudad ejemplares del Corán traducidos al francés, y que "os escravos, evidentemente muito pobres, mostram-se dispostos aos maiores sacrifícios para possuir êsse volumen" (Bastide, 1971, p. 205). También da cuenta de la existencia en torno a 1840 de una "mesquita maometana" en el mismo Río, donde se mezclarían creencias fetichistas con rudimentos del islam. Estos intentos sincréticos o de aculturación, podrían estar relacionados con la experiencia mística que para Bastide tiene que ver con un cierto sentimiento de "traición" a la ancestralidad fetichista en los lugares donde se produjo una islamización en África, sentimiento que se trasladó a una buena parte de los esclavos negros en Brasil (Bastide, 1976, pp. 87-93).

En algunos lugares de amplia impronta de la negritud, como Cuba o Brasil, no obstante, continuó la historia de fusiones de creencias "paganas" e islámicas. Quizás la lejanía y la esclavitud haya sido un factor añadido que evitó que la negritud americana acabase inserta en corrientes puramente musulmanas. Aunque en teoría en Brasil sí que existe un rastro del "islam negro", que debiera haber encauzado los deseos de libertad, como en África, fue el cristianismo católico o protestante quien lo hizo, a pesar de sus rigorismos morales y del control sacerdotal. En América la relación fue inversa a África, y el islam es el que se presentó como puritano frente a la laxitud católica. Dixit al respecto Roger Bastide:

Em relação aos negros fetichistas, os maometanos e os cristãos encontravam-se no Brasil numa situação absolutamente inversa daquela da África. Lá, o islamismo exige menos sacrifícios ao indivíduo que o catolicismo e o protestantismo. Elimina a mitologia para substituí-la por seu dogmatismo, traz alguns tabus, orações, mas não impõe um esforço moral angustiante, adapta-se a sensualidades do negro. Pelo contrário, no Brasil, era o catolicismo a religião mais acolhedora e mais tolerante. Exigia ao africano mais gestos e orações decoradas que era una verdadeira transformação da personalidade (...) Portanto, era o islamismo que aqui desempenhava o papel de religião puritana, com sua proibição da embriaguez, proibição essa inflexível para os infelizes escravos que buscavam na cachaça um fuga à realidade (Bastide, 1971, p. 218).

Otro aspecto que destacar será el semitismo, la presencia judía en Portugal que se trasladará a São Paulo, más alejada de los rigores inquisitoriales (Freyre, 2009, p. 58). Recordemos que el semitismo, que agrupaba a árabes musulmanes y cristianos y judíos, provenientes del área libanesa y siriaca, conformaría un mismo tipo de ideología en los años veinte. Estos intercambios eran antiguos, y se aceleraron con la ocupación francesa del Líbano en 1923, que provocaría la emigración conocida como de los "turcos" (Pastor, 2015). En Brasil predicó esta suerte de buena nueva pansemítica el exsacerdote maronita Habib Estéfano. En esa línea panarabista, Estéfano contrapone a las ideas de "algunos sociólogos de Europa, dominados irremisiblemente por la teoría moderna de las razas, [que] consideran a la América Hispana eternamente condenada al atraso y a la anarquía por juntar en su seno a razas antagónicas que jamás llegarán a constituir una sociedad 
suficientemente homogénea para poder subsistir y progresar", el ideal de fraternidad hispano-semítica, proponiendo "el encuentro y entrelazamiento de las razas (árabe, ibérica, hebrea) en la América Hispana [como] una fehaciente demostración de verdadero y generoso espíritu de humanidad" (Estéfano, 1931, p. 25). El semitismo de Estéfano no dejaba de ser una variante integradora de los pueblos mediterráneos bajo el dictado de un cierto idealismo antirracista proyectado hacia América. Habib Estéfano moriría en 1946 en la misma localidad brasileña donde había fallecido voluntariamente cinco años antes Stefan Zweig, Petrópolis (Río de Janeiro), cuando había llegado para continuar su prédica pan-andalusista, cuyo eje era la nostalgia de al-Ándalus, entre la comunidad "turca" (Moreyra, 1946, pp.179-184).

Esta mezcolanza disciplinar corre en paralelo con las obras de Gilberto Freyre y de Roger Bastide. El primero, Freyre, transitando entre la Historia propiamente dicha y la Sociología, que hoy día llamaríamos Antropología histórica con más propiedad que en su propia época, que al no haberse aún abierto un espacio epistémico bien definido para esta disciplina se inclina al ensayismo (Gomes, 2019). Y el segundo, Bastide, entre la Antropología de tradición clásica, consistente en estudiar sociedades no occidentales, y el psicoanálisis. Una diferencia, sin embargo, se impone: mientras Freyre era un académico reconocido en su propio país, con estancias en diversas universidades americanas y europeas, Bastide voluntariamente vivía una cierta marginalidad en el mundo universitario francés, donde no llegó a dejar escuela, si bien contribuyó notablemente a un debate que hoy no nos parece clausurado: el de la etno-psicología.

Dicho lo cual, no dejamos de observar la existencia de diferencias de las antropologías de Freyre y Bastide con las del cubano Fernando Ortiz y del polaco Bronislaw Malinowski respecto al concepto de acculturation, auspiciado en su momento por el estadounidense Melville J. Herskovits. De éste se muestra partidario total Roger Bastide, sobre todo cuando le hace frente al concepto político-cultural de negritude, muy popular en el momento de la descolonización. Para Bastide, la teoría de Herskovits al exponer el resultado del contacto con Occidente de la mentalidad negro-africana apuntaba mucho mejor que la de la negritude de Aimé Cesaire hacia el mundo de las transformaciones (Bastide, 1973, p. 146).

Partiremos de Herskovits -escribe programáticamente Bastide-. El vocablo 'reinterpretación' puede tomarse en dos sentidos; se puede pensar tanto en la reinterpretación de las realidades africanas en términos occidentales como en la reinterpretación de las realidades occidentales en términos africanos. Pero, de hecho, el verdadero interés de Herskovits radicó exclusivamente en el segundo aspecto citado, lo cual revela [...] cuando muestra que el doble hogar es una reinterpretación de la poligamia africana, o cuando en algunas formas de sincretismo descubre una reinterpretación del catolicismo o el protestantismo a través de la sensibilidad religiosa africana (Bastide, 1973, p. 147).

Herskovits, bajo el influjo del antirracismo de Franz Boas, estaba especializado en la negritud, y la noción de acculturation era el sostén de todo su ensamblaje teórico. Aplicó el concepto aculturación con un sentido asimilacionista, dejando ver que los negros norteamericanos tenían básicamente componentes sociales y físicos similares a los de los blancos, con lo que se alejaba de cualquier tentativa raciológica. Pero, añadía, que debían asimilarse a la cultura blanca, para lograr su plena integración. Estas tesis iniciales claramente asimilacionistas las fue abandonando Herskovits más adelante, conforme realizaba trabajos sobre el terreno. En primer lugar, en Surinam, donde se suponía que había una población negra, descendiente de esclavos, con un mínimo de contacto con los europeos. Luego durante una estancia en Costa de Oro, y en Haití, destacó mucho la componente negra de la cultura humana. Finalmente, en 1936, publicó "A memoramdum for study of acculturation", que apareció simultáneamente en cuatro revistas de Antropología, entre ellas en American Anthropologist y Man, las más punteras y referenciales del momento. A raíz de su artículo se pensó en convocar una reunión monográfica sobre la aculturación, que nunca tuvo lugar. Como esta no se pudo realizar, en 1938 publicó en solitario Acculturation: the study of culture contact, donde definió la aculturación como un contacto entre grupos humanos diversos. Con ello intentaba evitar el etnocentrismo asimilacionista que se le adjudicaba. En 1941, en The myth of negro past, sostenía que "asimilación y preservación no son excluyentes", intentado mantener el equilibrio entre ambos conceptos (Gershenhorn, 2004, pp. 65-95). Según A. Lupo, el sincretismo, bien entendido, podría caracterizarse por no haber llegado a un punto y final, sino por ser parte de una transición. Refiérese Lupo "a la situación en la que, durante 
un proceso de fusión entre elementos de tradiciones diversas, no se hubiera alcanzado aún dentro de la sociedad una plena comunión de las formas, y sobre todo de los significados del nuevo modelo híbrido" (Lupo, 1996, p. 18).

Fernando Ortiz le hizo saber a Bronislaw Malinowski que Herskovits le había mostrado su irritación por el empleo del término "transculturación", convertido en banderín de enganche para los combates intelectuales de Malinowski. Como dijimos, la confrontación de Herskovits con Malinowski fue de tal calibre, que el primero llegó a acusar veladamente al segundo de haber formulado opiniones jerarquizadoras sobre el contacto cultural, amparándose en las modas raciológicas de los años 1930. Por el contrario, Herskovits procuró acercarse a Ortiz, a quien no le atribuyó las malas intenciones que al jefe de filas funcionalista, aceptando incluso que el término aculturación tal como él lo empleaba se encontraba en la misma línea que el de transculturación (Herskovits, 1952, pp. 570-571). La polémica, pues, tenía algo de bizantinismo, marcado por la inquina personal.

Ahora bien, Bastide, antropólogo de formación clásica, a pesar de automarginación en el mundo académico francés, no veía con buenos ojos las tendencias ensayísticas, y por ende ideológicas de Freyre, que en cierto momento, presa de sus sentimientos pro-lusos lo llevaron a "comprender" la dictadura portuguesa de Salazar por su carácter "regeneracionista", y a verter algunas opiniones más "poéticas" que "científicas" (Gomes, 2010, p. 56). Es más, podríamos detectar en el Freyre "orientalista" el influjo del sebastianismo como un movimiento basado en el culto memorialístico al rey D. Sebastião, desaparecido en la batalla contra los "mouros" de Alcazarquivir en 1578 (Valensi, 1992). El sebastianismo tuvo sus momentos de esplendor bajo la dictadura del Estado Novo (Quadros, 1983). En línea similar, señala por su parte Mario Helio Gomes, que, en unas cuantas páginas de Antropología aplicada (2008), Bastide le hace una severa crítica a Freyre por sus derivas ideológicas, señalando que el lusotropicalismo no deja de ser una suerte de programa político vindicador de la mejor adaptación, gracias al contacto con los "mouros" de los portugueses en las colonias:

Sólo pretendíamos mostrar, al lado de dos aculturaciones planificadas que a pesar de la oposición en que se encuentran están de acuerdo en no admitir el cambio sino en las culturas exóticas [...], la existencia de una forma distinta de aculturación, esa a la cual Freyre dio el nombre de 'lusotropicalismo' y que culmina en una apología de la doble integración o amalgamiento, es decir, en resumidas cuentas, una apología de la culturas a las que se califica como 'marginales' respecto, simultáneamente, de la cultura occidental y de las culturas indígenas (Bastide, 1977, p. 92).

Hoy día está más claro el paso de esta vinculación entre el lusotropicalismo y el apoyo a la centralidad del Portugal dictatorial de Antonio de Oliveira Salazar (de 1933 a 1968) (Oliveira, 2015, p. 75). Amurabi Oliveira es muy crítico asimismo con el "oriente" de Freyre que considera producto en muchas ocasiones de su sola imaginación, atemporal y al servicio de un mito intemporal sin contrastar históricamente. Sin entrar en ese debate, para mi ahistórico, pues elude comprender a Freyre en su tiempo, existe una pulsión en este para construir un axis mundi en torno a Brasil, el cual procede del Manifiesto Regionalista de 1926 lanzado en el congreso de Recife, que encuentra su paralelo con la Exposición iberoamericana de 1929 en Sevilla. En ambos momentos, a un lado y otro del Atlántico, se pide por parte de las élites profesorales y académicas, un esfuerzo por establecer ideas-fuerza, en el sentido otorgado a este concepto por el sociólogo francés Alfred Fouillée (1890), para situar el antiguo y nuevo iberismo neocolonial en el centro de los combates, frente a los nuevos colonialismos e imperialismos francés, británico y norteamericano en ascenso. Allí, en 1929, dirá Freyre:

Donde a necessidade deste Congresso de Regionalismo definir-se a favor de valores assim negligenciados e não apenas em prol das igrejas maltratadas e dos jacarandás e vinháticos, das pratas e ouros de família e de igreja vendidos aos estrangeiros, por brasileiros em quem a consciência regional e o sentido tradicional do Brasil vem desaparecendo sob uma onda de mau cosmopolitismo e de falso modernismo. É todo o conjunto da cultura regional que precisa de ser defendido e desenvolto (Freyre, 1955, p. 54). 
En este sentido, para algunos autores la trayectoria de Freyre no se puede desvincular de la nueva vida del viejo imperialismo neo-portugués, que exalta un pasado "oriental" a su acomodo (Castelo, 2008).

Un aspecto que nos puede servir para establecer un diálogo con la obra crítica con el concepto de aculturación de Herskovits, tan apreciado al unísono tanto por Freyre como por Bastide, es el destino del café, un producto identificado y naturalizado con el Brasil, y sin embargo de procedencia africana, que acabó completamente transculturado, como la caña de azúcar o los tambores africanos en Cuba. La invención de la palabra "transculturación", logró su formulación definitiva en el libro más trascendente del antropólogo e historiador cubano Fernando Ortiz (1881-1969), Contrapunteo cubano del tabaco y el azúcar, publicado en 1940, con prólogo de B. Malinowski. Esta transculturación tiene en común con Cuba tanto el ingenio, como lugar de explotación agrícola humana, como la esclavitud, como fuerza de trabajo. Veamos sintéticamente lo que entiende por transculturación Fernando Ortiz:

Entendemos que el vocablo transculturación expresa mejor las diferentes fases del proceso transitivo de una cultura a otra, porque éste no consiste solamente en adquirir una distinta cultura, que es lo que en rigor indica la voz angloamericana acculturation, sino que el proceso implica también necesariamente la pérdida o desarraigo de una cultura precedente, lo que pudiera decirse una parcial desculturación, y, además, significa la consiguiente creación de nuevos fenómenos culturales que pudieran denominarse de neoculturación (Ortiz, 2002, p. 260).

Evidentemente, Freyre y Bastide estaban familiarizados con la literatura de Fernando Ortiz, quien un poco mayor que ellos, había llevado a cabo una obra anti-raciológica, en la que destaca El engaño de las razas, publicada en 1946. Este largo excurso de Ortiz contra el racismo biológico en parte es una reacción a la idea de raza que él mismo había manejado en su primer libro Hampa afrocubana. Los negros brujos. Apuntes para un estudio de etnología criminal, publicado en 1906, donde se mostraba partidario de la Antropología criminológica italiana a lo Cesare Lombroso. En 1946, en pleno reflujo del racismo biológico, sostenido por las potencias nazi-fascistas, Fernando Ortiz se muestra ahora partidario de eliminar la palabra "raza" del argot común:

La batalla semántica por la 'democracia' es tan importante como la guerreada con los armamentos que dan muerte. Y lo mismo ocurre con el vocablo 'raza'. Mientras éste no sea despojado de las mentiras con que se le reviste para engañar a los pueblos, seguirá con su congénita peligrosidad social (Ortiz, 1946, p. 416).

En este texto, aunque no recurra a Freyre, Ortiz está en línea con denunciar la noción de raza empleada principalmente por los genetistas, pero también critica una noción que quizás hubiese sido más del gusto del brasileño: las "razas culturales" o como él mismo dice "las razas de las almas". Este tipo de racismo, para Ortiz, procede del fracaso del racismo genético, y se refugia en el mundo psíquico, incluso, como en el caso francés, defendiendo la existencia de razas basadas en la mezcla genética (Ortiz, 1946, pp. 205-223).

La palabra ha tenido otros usos, no menos sintomáticos. El uruguayo Ángel Rama, tomando la palabra de Ortiz "transculturación" y aplicándola a la literatura y la crítica literaria latinoamericana, ve una estrecha relación entre la democratización y el surgimiento de un pensamiento y escritura continental (Rama, 1985). Previamente al pensamiento de Rama, en los años 1930 a 1950, asistimos al intento categorial de trazar en diferentes ámbitos iberoamericanos un sentido colectivo, un terreno de diálogo. Allá la raza y la mezcla aparecen nucleares. Arguedas y Mariátegui también entrarán en este dominio explicativo. Mariátegui se sublevaba contra todo exotismo literario, y veía en el indigenismo una fuerza política transformadora: "EI indio no representa únicamente un tipo, un tema, un motivo, un personaje. Representa un pueblo, una raza, una tradición, un espíritu. No es posible, pues, valorarlo y considerarlo, desde puntos de vista exclusivamente literarios, como un calor o un aspecto nacional" (Mariátegui, 1975, p. 273). Arguedas, por su parte, había nacido en 1911 en Andahuaylas, cerca de Cuzco, un pueblo copado por una soberbia iglesia barroca, que resume en sus retablos la mezcla cultural entre la indianidad y la españolidad. Hasta los ocho años sólo hablaba quechua, al mezclarse en su soledad infantil con los campesinos cuzqueños dada su 
orfandad, ya que había perdido tempranamente a su madre, y que su padre, un pequeño notable local de origen español, estaba con frecuencia ausente en viajes por las sierras. Desde el punto de vista expresivo Arguedas no renuncia al español, aunque sabe que los indios de muchas de las zonas que él refleja en su literatura eran monolingües y sólo se expresan en quechua. Se ha señalado por ello la vinculación entre el cronista Guamán Pomá (1534-1615) y Arguedas, ya que los dos van a la búsqueda en tiempos diferentes de unas formas expresivas transculturales que reflejasen lo andino. Desde luego, el intento de Arguedas, según Ángel Rama, debe ser catalogado de "transculturador". El propio Arguedas había adoptado el concepto, señalando de paso que él no era un "aculturado" (Cruz, 1990). La transculturación de Arguedas se observa en la búsqueda de ese modo de expresión literaria particular que consigue, según él, tras cinco años encaminados a "desgarrar los quechuismos y convertir el castellano literario en el instrumento único". Alcanza esta dimensión en dos obras suyas, Agua y Yawar fiesta, reconociendo que la situación del creador en el medio andino, cuando es bilingüe, y por tanto con doble pertenencia cultural, es una "vía crucis heroica y bella". A este propósito otra expresión suya es "desgarramiento" para defender la invasión del castellano por profundos "quechuismos", que hagan hablar a la colectividad (Arguedas, 1968, pp. 19-20). No se trata de un "indigenismo" ni de un "regionalismo" ni de un "telurismo", se trata de conseguir hacer hablar a las culturas orales mediante la literatura, empleando el vehículo de la transculturación. Para Arguedas la integración se hará por la convergencia entre los diversos actores sociales y culturales en la "insurgencia" (Arguedas, 1989, p. 9-20). De alguna manera, y dada la desposesión del indígena, el antropólogo brasileño Darcy Ribeiro hablará de un proceso de "transfiguración étnica" por el cual "tomados de las antiguas y según valores y criterios que provienen de las mismas, permite a las etnias tribales guardar cierta continuidad a lo largo de la transfiguración" (Ribeiro, 1971, p. 28). Juegos que transformaciones, por consiguiente, que afectan directamente al contexto en el cual insertamos las obras de Freyre y Bastide.

Finalmente, como granadino, sensible a la cuestión árabe en buena lógica, el recurso de Freyre a la figura de Ángel Ganivet (1865-1898) no deja de atraerme. No es la primera vez que veo esa alusión. Ganivet fue muy leído en Brasil, en particular por Gilberto Freyre, que tenía en gran estima el ensayismo español que giró en torno a las generaciones del 98 y del 27 (Rugai, 1998). En su biblioteca Freyre tenía anotadas las obras de Ganivet, en particular el Idearium español y Granada la bella. Con ella se familiariza con el ateo y "anarconirvánico", en expresión propia, Ángel Ganivet, enfrentado al castellanizado y cristianizado Unamuno. Y aquí introduce, en la tensión histórica entre Castilla y Portugal, interpretada en el Idearium español ganivetiano, el siguiente argumento:

Nosotros ya hemos señalado este odio político de Portugal. Pero este rechazo, ni aquel más fundamental del moro, lograrán separar a Portugal de las dos grandes civilizaciones, hispánica y bereber, que son como sus civilizaciones paterna y materna. Portugal se forma políticamente contra ellas, pero su carácter permanecerá influenciado por ellas (Freyre, 2009, pp. 236-237).

Ganivet, por su parte, consideraba que España no se podía entender sin su pasado árabe: "Así pues, los que con desprecio y encono o sistemáticos descartan de nuestra evolución espiritual, la influencia arábiga, cometen un crimen psicológico, y se incapacitan para comprender el carácter español" (Ganivet 1897a, p. 160). Ganivet, no obstante esta opinión, no cae en falsos orientalismos: "Granada continúa -escribirásiendo una ciudad morisca sin moros, porque algo se ha de decir para entretener al honrado público" (Ganivet, 1971, p. 81). Elide Rugai, al señalar la gran influencia que Ganivet ejerce sobre Freyre, subraya que "creo que él fue uno de los responsables de la exploración que Freyre hizo del orientalismo de nuestra cultura" (Rugai, 1998, p. 85). Quizás otro de los aspectos más destacables de esa influencia tenga relación directa con la concepción de Freyre sobre los modos de colonización.

Para el Ganivet de La conquista del reino de Maya por el último conquistador español Pío Cid, el colonialismo español fue "amoroso". Probablemente Freyre leyó también la citada obra ganivetiana. Estaba de acuerdo en lo sustancial con las tesis ganivetianas que defendían el colonialismo el "espiritual" frente a la voracidad del colonialismo europeo. Para marcar las diferencias entre España y los otros países colonizadores, Pío Cid, el alter ego de Ganivet, en sus disquisiciones en el reino Maya hablará de un estadio erótico de la civilización, según él, el más noble, si hemos de compararlo con el que más detestaba, el comercial (Ganivet 
1897b). No obstante, aunque no hubiese leído esta novela, son muchas las alusiones al problema colonial, y la necesidad de colonizar "a la antigua" que señala Ganivet en el Idearium.

Como quedó señalado, a diferencia de Freyre, Ortiz pone distancias con conceptos de su tiempo como aculturación, pero también con futuras asimilaciones de otros como mestizaje. No obstante, en el debate actual, el concepto de hibridez, basado en el de transculturación, ha ganado terreno frente a otros. Este último, formulado como culturas híbridas, incluye, según García Canclini, lo que no existía en su tiempo: la modernidad radical o posmodernidad, con la presencia de las transformaciones que aporta lo mediático (García Canclini, 2001, p. 22). También el de deculturación o desposesión cultural enarbolado por el también cubano Moreno Fraginal (1996, p. 31).

Pero no por estas críticas, en parte acertadas, debemos perder de vista las posibilidades analíticas contextualizadas en su tiempo que ofrecen obras como la de Gilberto Freyre, con relación a su valoración del Oriente. Con esta valoración estaba poniendo en el horizonte la posibilidad de hacer un polo del conocimiento liberado del imperialismo cultural imperante, de matriz anglofrancesa (González Alcantud, 2013).

En ese contexto, autores difícilmente clasificables como Gilberto Freyre, o su admirado Ángel Ganivet, pueden ser revisitados, en la línea libertaria insinuada por L. Febvre. Si en todos ellos la idea preponderante es la del principio de mezcolanza o mestizaje frente a todo racismo fundacional, esta idea puede seguir siendo excitante, a condición de como señala Serge Gruzinski, hoy día, el proceso de mestizaje americano sea contemplado como "una reacción de supervivencia a una situación inestable, imprevista y grandemente imprevisible” (Gruzinski, 2012, p. 104).

Ahora bien, hoy como antes, una dificultad se alza ante nosotros para establecer una comunidad iberoamericana de pensamiento capaz de elaborar un pensamiento propio: la libre circulación de las ideas y la centralidad de los debates. Una dificultad, por lo demás, que asimismo se alzaba y sigue alzando, entre ellos, la comunidad en lengua inglesa y francesa, y nosotros, los hablantes de las lenguas de raíz ibérica. A romper ese círculo infernal puede servir revisitar obras como la Freyre y Bastide en su concepción del "oriente abrasileñado". 


\section{REFERENCIAS BIBLIOGRÁFICAS}

Arguedas, J. M. (1968). La novela y el problema de la expresión literaria en el Perú. Yawar fiesta (pp. 11-21). Santiago de Chile: Editorial Universitaria.

Arguedas, J. M. (1989). Indios, mestizos y señores. Lima: Ed. Horizonte.

Bastide, R. (1971). O Islã Negro no Brasil. As religiones africanas no Brasil (pp. 203-218). São Paulo: Editora da Universidade de São Paulo.

Bastide, R. (1973). El próximo y el extraño. El encuentro de civilizaciones. Buenos Aires: Amorrortu.

Bastide, R. (1977). Antropología aplicada. Buenos Aires: Amorrortu.

Castelo, C. (2008). Outro no labirinto imperial: orientalismo e luso-tropicalismo. In R. Carmo; D. Melo \& R. Llera Blanes (Eds.). A globalização no divã (pp. 295315). Lisboa: Tinta-da-China.

Cruz Leal, P. I. (1990). Dualidad cultural y creación mítica en José María Arguedas. San Cristóbal de la Laguna: Universidad de la Laguna.

De Diego, A. (2019). Sufismo negro. Córdoba: Almuzara.

Estéfano, H. (1931). Los pueblos hispano-americanos. Su presente y su porvenir. México: Ediciones Culturales.

Fouillée, A. (1890). L'Évolutionnisme des idées-forces. París: Felix Alcan.

Freyre, G. (1955). Manifesto Regionalista de 1926. Río de Janeiro: Ministério da Educação e Cultura.

Freyre, G. (1971). Nôvo mundo nos trópicos. São Paulo: Ed. Nacional/Ed. da USP.

Freyre, G. ([1952] 2009). Maîtres et esclaves. La formation de la société brésilienne (Trad. R. Bastide). París: Gallimard.

Freyre, G. ([1936] 2013). Sobrados e mucambos. Decadência do patriarcado rural e desenvolvimento do urbano. S/l.: Ed. de Roberto DaMatta, Edson Nery de Fonseca y Gustavo Henrique Tuna.

Ganivet, A. (1897b). La conquista del reino de maya por el último Conquistador español, Pío Cid. Madrid: Ribadeneira.

Ganivet, A. ([1905] 1971). Cartas finlandesas. Hombres del Norte. Madrid: Austral.

Ganivet, A. G. (1897a). Idearium español. Granada: Sabatel.

García Canclini, N. ([1990] 2001). Culturas híbridas. Estrategias para entrar y salir de la modernidad. Barcelona: Paidós.
Gershenhorn, J. (2004). Melville J. Herskovits and the Racial Politics of Knowledge. Lincoln: University of Nebraska Press.

Gomes de Lima, M. H. (2008). Antropología aplicada en Iberoamérica. Recife: Fundação Joaquim Nabuco/ Editora Massangana.

Gomes de Lima, M. H. (2010). Gilberto Freyre. Recife: Fondação Joaquim Nabucco.

Gomes de Lima, M. H. (2019). Gilberto Freyre: la esclavitud como gozne entre la historia y la socioantropología. In J. A. González Alcantud (Ed.). El rapto de la Historia. Introducción a un debate con la Antropología (pp. 223248). Granada: Editorial Universidad de Granada.

González Alcantud, J. A. (1997). Ángel Ganivet ante la polémica de los modos de colonización. A propósito de 'La conquista del Reino de Maya por Pío Cid'. Rilce, 13(2), 75-96.

González Alcantud, J. A. (2011). Racismo elegante. De la teoría de las razas culturales a la invisibilidad del racismo cotidiano. Barcelona: Bellaterra.

González Alcantud, J. A. (2013). Itinerarios islámicos descoloniales en Iberoamérica. De la sombra morisca a la fraternidad semítica. In I. Rodríguez \& J. Martínez (Eds.) Estudios transatlánticos poscoloniales (Vol. 3., pp. 303-327). Barcelona: Anthropos.

Gruzinski, S. (2012). La pensé métisse. París: Fayard.

Herculano, A. (1987). História de Portugal. Libro VIII. A Sociedade. Primera época. Os Concelhos. Lisboa: Círculo de Leitores.

Herskovits, M. J. ([1948] 1952). El hombre y sus obras. Las ciencias de la antropología cultural. México: FCE.

Hertel, P. (2015). The Crescent Remembered: Islam and Nationalism on the Iberian Peninsula. Brighton: Sussex University Press.

Lupo, A. (1996). Síntesis controvertidas. Consideraciones en torno a los límites del concepto de sincretismo. Revista de Antropología Social, $n^{\circ} 5,11-38$.

Mariátegui, J. C. ([1928] 1976). Siete ensayos de interpretación de la realidad peruana. Barcelona: Crítica.

Monteil, V. (1964). L'Islam noir. París: Seuil.

Morandeyra, M. (1946). Habib Estéfano en mi vida. Ante la conciencia de las colectividades de habla árabe en América. Buenos Aires: Artes Gráficos B.U. Chiesino.

Moreno Fraginals, M. (1996). Agentes culturales y deculturación. In M. Moreno Fraginals (Ed.). África en América Latina. Madrid: Siglo XXI. 
Oliveira, A. (2015). O Oriente, o Luso e o Brasil na Obra de Gilberto Freyre. Asian Journal of Latin American Studies, 288(4), 73-89.

Ortiz, F. (1946). El engaño de las razas. La Habana: Ed. Páginas.

Ortiz, F. ([1940] 2002). Contrapunteo cubano del tabaco y el azúcar. Madrid: Cátedra.

Pastor de María y Campos, C. (2015). El modernismo en un Atlántico moro: historia de viaje. J. A. González Alcantud \& S. Rojo Flores (Eds.). Andalusíes. Antropología e historia cultural de una elite magrebí (pp. 241-277). Madrid: Abada.

Quadros, A. (1988). Poesia e Filosofia do Mito Sebastianista. Lisboa: Guimarães.

Rama, A. (1985). Las máscaras democráticas del modernismo. Montevideo: Fundación Ángel Rama.

Ribeiro, D. (1971). Fronteras indígenas de la civilización. México: Siglo XXI.

Rugai Bastos, E. (1998). Viajes de Ángel Ganivet a Brasil. Fundamentos de Antropología, $\mathrm{n}^{\circ}$ 8/9, 75-86.

Valensi, L. (1992). Fables de la mémoire. La glorieuse bataille des trois rois. París : Seuil.

Zweig, S. (1941). Brasil, país do futuro. Recuperado de [http://www.ebooksbrasil.org/adobeebook/paisdofuturo. pdf]. Consultado [10-02-2020]. 